\title{
Preparation and Investigation of Pd/Ti-SBA-15 Catalysts for Catalytic Oxidation of Benzene
}

\author{
Chi He, Peng Li, Jie Cheng, Jinjun Li, and Zhengping Hao \\ Department of Environmental Nano-Materials, Research Center for Eco-Environmental Sciences, Chinese Academy of Sciences, \\ Beijing 100085, People’s Republic of China; zpinghao@rcees.ac.cn (for correspondence)
}

Published online 24 March 2010 in Wiley Online Library (wileyonlinelibrary.com). D0I 10.1002/ep.10427

The feasibility of $P d / T i-S B A-15$ catalysts in the elimination of benzene was explored comprebensively. The effects of the titanium incorporation on catalyst physicochemical property and activity were investigated by X-ray diffraction, $\mathrm{N}_{2}$ adsorption/desorption, Fourier transform infrared spectroscopy, DRUV-vis, $\mathrm{NH}_{3}$-TPD, scanning electron microscope, and transmission electron microscope techniques. Only a certain quantity of titanium can be incorporated into the support, and titanium has a positive influence on active phase dispersion. Titanium-modified catalysts possess larger pore diameter than the pure $P d / S B A-15$ and titanium can introduce the acid sites to the support. The evaluation result shows that the titanium incorporation can noticeably improve the catalytic activity, and all evaluated catalysts possess excellent stability, without obviously activity loss during 60 b test. (c) 2010 American Institute of Chemical Engineers Environ Prog, 29: 435-442, 2010

Keywords: titanium-modified, SBA-15, mesoporous molecular sieves, $V O C$

\section{INTRODUCTION}

The emission of volatile organic compounds (VOCs) into atmosphere has a great negative impact on the environment and public health because of their toxic, mutagenic, and carcinogenic nature. Moreover, the VOCs can act indirectly as the ozone and smog precursors. As a consequence, proper control of VOCs emission is required. Many techniques have been developed to eliminate VOCs including

\footnotetext{
Additional Supporting Information may be found in the online version of this article.

(c) 2010 American Institute of Chemical Engineers
}

the non-destructive and destructive approaches. The non-destructive methods retain VOCs composition. In contrast, the destructive approaches (such as thermal incineration and catalytic oxidation) transform VOCs into inert or less dangerous compounds. However, thermal incineration consumes a large amount of energy and leads to lots of toxic byproducts although it is an effective approach to convert VOCs into $\mathrm{CO}_{2}$ and $\mathrm{H}_{2} \mathrm{O}$ [1]. In comparison with the thermal incineration, the catalytic oxidation is an energy-saving and high-efficiency technique. Furthermore, the selectivity of catalytic reaction could be controlled.

More attention has been paid to develop effective catalytic materials and improve their catalytic performances, such as noble metals and metal oxides catalysts [2, 3]. Microporous zeolites with uniform pores have been widely used as industrial catalysts for removing of VOCs [4]. However, these catalysts cannot effectively catalyze large VOCs molecules because of their relatively small pore size. Fortunately, the discovery of mesoporous silica materials with uniform pore diameter in the range of 2.0-10.0 $\mathrm{nm}$ (such as MCM-41) offers a good opportunity for silicate as versatile catalysts or supports for oxidation of large VOC molecules. However, the weak stability of these materials limits their extensive applications [5]. More recently, SBA-15 with uniform and large pore channels (more suitable for deal with bulky VOCs molecules), thick pore wall and high hydrothermal stability has been successfully synthesized [6]. Pure SBA-15 is inert in oxidation of VOCs, and many hetero-atoms have been successfully incorporated into SBA-15 in the past decades [7-10]. Yang et al. [11] synthesized the $\mathrm{CuO} / \mathrm{SBA}-15$ catalyst for catalytic oxidation of benzene. $\mathrm{Mu}$ et al. [3] have investigated the Co/Ce-SBA-15 materials and their catalytic activity 

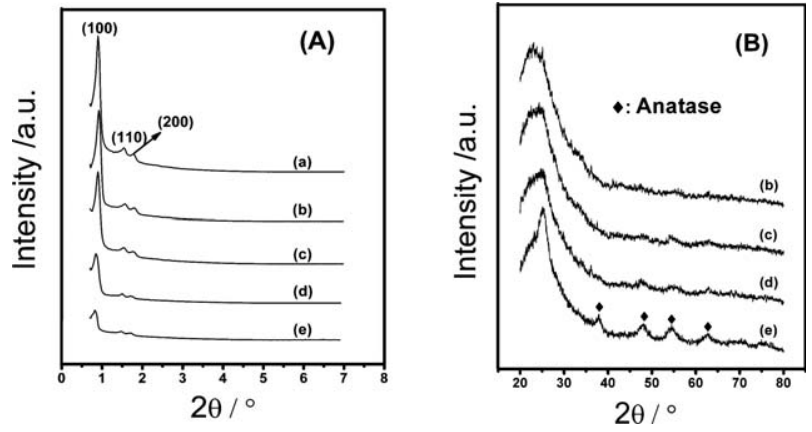

Figure 1. A: Small-angle XRD patterns of (a) Pd/SBA15, (b) Pd/Ti-SBA-15(80), (c) Pd/Ti-SBA-15(40), (d) Pd/Ti-SBA-15(20), and (e) Pd/Ti-SBA-15(10); B: Wideangle XRD patterns of (b) Pd/Ti-SBA-15(80), (c) Pd/ Ti-SBA-15(40), (d) Pd/Ti-SBA-15(20), and (e) Pd/TiSBA-15(10).

in elimination of benzene. The catalytic oxidation of benzene on two types of mesoporous Co/SBA-15 catalysts was reported by Li et al. [12]. It is well known that $\mathrm{TiO}_{2}$ is good support for VOCs catalytic oxidation, which was extensively investigated in recent decades [13-15]. Zepeda et al. [16] revealed that the presence of $\mathrm{Ti}^{4+}$ ions could strengthen the metalsupport interaction, and titanium atoms could provide better dispersion for active phases over the support $[17,18]$. However, the Ti-modified SBA-15 mesoporous materials have been seldom reported in catalytic oxidation of benzene-like VOCs.

In this work, we attempt to direct synthesis the TiSBA-15 mesoporous support with high Ti content (the $\mathrm{Si} / \mathrm{Ti}$ molar ratio $=10$ ), and the feasibility of asprepared materials in the elimination of benzene (a typical VOCs and widely used in a great number of chemical processes) was further investigated.

\section{EXPERIMENTAL}

\section{Catalyst Preparation}

Ti-SBA-15 samples with different $\mathrm{Si} / \mathrm{Ti}$ molar ratios were synthesized using the P123 (Sigma-Aldrich) as the structure-directing agent, and using the tetrabutyl titanate (TBOT) and tetraethyl orthosilicate (TEOS) as titanium and silica sources, respectively. The typical synthesis procedure was as follows: $1 \mathrm{~g}$ of P123 was dissolved in $35 \mathrm{~mL}$ of $\mathrm{HCl}$ aqueous solution at $\mathrm{pH} 2.0$ at room temperature, followed by addition of $2.3 \mathrm{~mL}$ of TEOS and mixed at $35^{\circ} \mathrm{C}$. Then, a given amount of TBOT was added to the acidic solution under vigorous stirring at $35^{\circ} \mathrm{C}$ for $24 \mathrm{~h}$. Then, the mixture was transferred into an autoclave and aged at $100^{\circ} \mathrm{C}$ for $48 \mathrm{~h}$. The solid product was filtered and thoroughly washed with deionized water, and dried at $100^{\circ} \mathrm{C}$ overnight. Then the material was calcined in a muffle furnace at $500^{\circ} \mathrm{C}$ for $4 \mathrm{~h}$ with a heating rate of $5^{\circ} \mathrm{C} / \mathrm{min}$, and the mesoporous Ti-SBA- 15 samples were finally obtained.

$\mathrm{Pd} /$ Ti-SBA-15 catalysts with a Pd loading of 0.3 wt $\%$ were prepared by impregnating these supports with a $\mathrm{PdCl}_{2}$ aqueous solution and drying at $100^{\circ} \mathrm{C}$
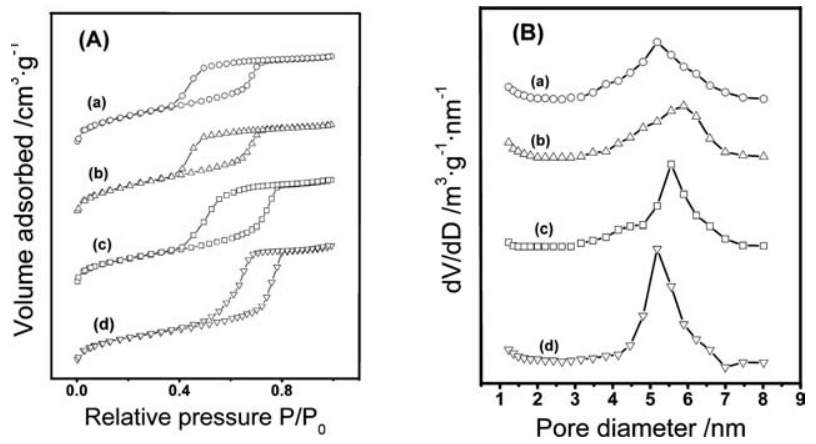

Figure 2. $\mathrm{N}_{2}$ adsorption/desorption isotherms (A) and pore size distribution (B) of (a) Pd/Ti-SBA-15(10), (b) Pd/Ti-SBA-15(20), (c) Pd/Ti-SBA-15(40), (d) Pd/TiSBA-15(80).

overnight, and then being calcined at $500^{\circ} \mathrm{C}$ for $4 \mathrm{~h}$ and being reduced in a pure hydrogen stream (30 $\mathrm{mL} / \mathrm{min}$ ) at $480^{\circ} \mathrm{C}$ for $2 \mathrm{~h}$. The solid products are denoted Pd/Ti-SBA-15(x), where $\mathrm{x}$ stands for the $\mathrm{Si} /$ $\mathrm{Ti}$ molar ratio. For comparison purposes, the $\mathrm{Pd} /$ $\mathrm{TiO}_{2}, \mathrm{Pd} / \mathrm{SBA}-15, \mathrm{Pd} / \mathrm{Ti}-\mathrm{SBA}-15(\mathrm{y})$ (y stands for the calcinations time $(1-8 \mathrm{~h})$ ), and Pd/Ti-SBA-15(z) (z stands for the calcinations temperature $\left(400-800^{\circ} \mathrm{C}\right)$ ) samples were also prepared. The pure $\mathrm{TiO}_{2}$ was prepared according to the procedure reported by Wang [19], and the pure SBA-15 was synthesized following the same procedure as described above without adding the titanium source.

\section{Catalyst Characterizations}

Small-angle X-ray diffraction (XRD) patterns were recorded on a Rigaku TTR2 powder diffraction system using $\mathrm{Cu} \mathrm{K \alpha}$ radiation $(\lambda=0.15418)$ in the $2 \theta$ range of $0.7-7^{\circ}$ with a scanning rate of $0.5^{\circ} / \mathrm{min}$. The wideangle XRD patterns were measured on a Rigaku powder diffractomter (D/MAX-RB) using $\mathrm{Cu}$ K $\alpha$ radiation in the $2 \theta$ range of $20-80^{\circ}$ with a scanning rate of $4^{\circ} /$ min. The exact Pd wt \% in all calcined samples was determined by inductively coupled plasma optical emission spectroscopy (ICP-OES) on an OPTIMA 2000. The $\mathrm{N}_{2}$ adsorption/desorption isotherms were measured at $77 \mathrm{~K}$ on a NOVA1200 gas sorption analyzer. All samples were degassed under vacuum at $300^{\circ} \mathrm{C}$ for $3 \mathrm{~h}$ before measurement. The infrared spectra were recorded on a Bruker Tensor 27 using DRIFT technique, scanned from 2000 to $600 \mathrm{~cm}^{-1}$. All samples were ground with $\mathrm{KBr}$ and pressed into a thin wafer. Diffuse reflectance UV-vis spectra were collected on a Hitachi UV3000 spectrophotometer scanning from 190 to $600 \mathrm{~nm}$. $\mathrm{NH}_{3}$-TPD was performed on a Micromeritics 2720 . Typically, $0.1 \mathrm{~g}$ of sample was pre-treated in a helium stream $(50 \mathrm{~mL} / \mathrm{min})$ at $300^{\circ} \mathrm{C}$ for $1 \mathrm{~h}$ and then cooled down to room temperature prior to adsorption of $\mathrm{NH}_{3}\left(\mathrm{NH}_{3} / \mathrm{He}\right.$ of 1:49 (v/v)) for $1 \mathrm{~h}$. After saturated with $\mathrm{NH}_{3}$, the catalyst was flushed with $\mathrm{He}(50 \mathrm{~mL} /$ $\mathrm{min}$ ) for $1 \mathrm{~h}$ at room temperature to remove the physisorbed $\mathrm{NH}_{3}$. After that, the desorption pattern was recorded from $150^{\circ} \mathrm{C}$ to $550^{\circ} \mathrm{C}$ at a heating rate of 
Table 1. Physicochemical property of catalysts.

\begin{tabular}{|c|c|c|c|c|c|c|}
\hline Catalysts & Si/Ti molar ratio & Pd" $^{*}$ (wt \%) & $C_{\mathrm{t}}^{* *}\left({ }^{\circ} \mathrm{C}\right)$ & $S_{\mathrm{BET}^{\dagger}}^{\dagger}\left(\mathrm{m}^{2} / \mathrm{g}\right)$ & $D_{\mathbf{v}}^{\dagger+}\left(\mathrm{cm}^{3} / \mathrm{g}\right)$ & $D_{\mathrm{p}}^{\dagger}(\mathrm{nm})$ \\
\hline $\mathrm{Pd} / \mathrm{TiO}_{2}$ & - & 0.29 & 500 & 4.35 & 0.121 & 3.7 \\
\hline $\mathrm{Pd} / \mathrm{SBA}-15$ & - & 0.28 & 500 & 784.6 & 1.041 & 5.2 \\
\hline \multirow{8}{*}{$\mathrm{Pd} / \mathrm{Ti}-\mathrm{SBA}-15$} & 10 & 0.28 & 500 & 688.2 & 0.612 & 5.1 \\
\hline & 20 & 0.29 & 500 & 736.4 & 0.832 & 5.8 \\
\hline & 40 & 0.27 & 500 & 740.7 & 0.846 & 5.5 \\
\hline & 80 & 0.28 & 500 & 761.2 & 0.898 & 5.2 \\
\hline & 20 & 0.29 & 400 & 702.1 & 0.718 & 5.3 \\
\hline & 20 & 0.29 & 600 & 729.6 & 0.793 & 5.7 \\
\hline & 20 & 0.29 & 700 & 595.8 & 0.554 & 5.4 \\
\hline & 20 & 0.29 & 800 & 565.4 & 0.513 & 5.3 \\
\hline
\end{tabular}

*Actual Pd contents obtained by the ICP-OES analysis.

$* *$ Calcination temperature.

${ }^{\dagger}$ BET specific surface area, which was calculated by the linear part of the BET equation $\left(P / P_{0}=0.05-0.25\right)$.

ttTotal pore volume obtained at $P / P_{0}=0.99$.

${ }_{\mathrm{B}} \mathrm{BJH}$ pore diameter calculated from the desorption branch using the Barrett-Joyner-Halenda (BJH) method.

$10^{\circ} \mathrm{C} / \mathrm{min}$. The SEM was performed on a Hitachi S$3000 \mathrm{~N}$ instrument operating at $20 \mathrm{kV}$. TEM images were collected on a Hitachi H-7500 microscope operating at an accelerating voltage of $80 \mathrm{kV}$.

\section{Catalytic Oxidation Activities}

All evaluation experiments were performed in a continuous-flow fixed-bed reactor under atmospheric pressure. It consists of a $6 \mathrm{~mm}$ i.d. stainless steel tube that was placed in a tubular electrical furnace. The temperature of catalyst bed and tubular electric furnace were monitored automatically with E-type thermocouples, respectively. One air stream was passed through a saturator to make a mixed gas containing high concentration of benzene and then further diluted with another air stream before reaching the reaction bed. The total flow rate was set to be 300 $\mathrm{mL} / \mathrm{min}$ with the benzene concentration of $1500 \mathrm{ppm}$ by adjusting the two flow rates above.

In each test, $300 \mathrm{mg}$ of catalyst $(40-60 \mu)$ was placed at the center of the reactor and the gas hourly space velocity (GHSV) for all tests was kept at 26,000 $\mathrm{h}^{-1}$. Before each test, the catalytic bed temperature was risen to $130^{\circ} \mathrm{C}$ with the feed stream passing (no oxidation was detected) and stabilized for $30 \mathrm{~min}$, and then the catalyst bed temperature was risen with a heating rate of $5^{\circ} \mathrm{C} / \mathrm{min}$ to the next point and stabilized for $20 \mathrm{~min}$ prior to online analysis of the effluent gas composition in an Agilent gas chromatograph equipped with an FID and a TCD. The VOC concentrations in the feed and effluent streams were determined with the FID after being separated in an ABGASPRO capillary column, and $\mathrm{CO} / \mathrm{CO}_{2}$ in the effluent stream were separated in a TDX-01 column and their concentrations were determined with the TCD.

Long-term stability tests (60 h) of Pd-SBA-15 and $\mathrm{Pd} /$ Ti-SBA-15(20) were carried out with the benzene feed concentration of $1500 \mathrm{ppm}$. The GHSV was fixed at $26,000 \mathrm{~h}^{-1}$, and the operation temperature was kept at 200 and $240^{\circ} \mathrm{C}$, respectively.

\section{RESULTS AND DISCUSSION}

\section{XRD}

Figure 1A shows that all Pd/Ti-SBA-15(x) samples display three well-resolved diffraction peaks, which can be indexed as the (100), (110), and (200) diffractions of the two-dimensional hexagonal mesostructure that match well with the pure SBA-15 [20], indicating that titanium did not destroy the original structure of the support. However, the structural order of support decreased with the increasing of $\mathrm{Ti} / \mathrm{Si}$ ratio (Figure 1A) [21]. Moreover, the (100) peak moved from 0.98 to $0.84^{\circ}$ when the $\mathrm{Si} / \mathrm{Ti}$ molar ratio decreases (Figure 1A), indicating that the presence of $\mathrm{Ti}^{4+}$ in SBA-15 framework as the $\mathrm{Ti}-\mathrm{O}$ bond distance is larger than the $\mathrm{Si}-\mathrm{O}$ bond. Besides, both the calcination temperature and calcination time have negligible influences on the ordered mesoporous structure of SBA-15 (Supplementary material: Figure $\mathrm{S} 1$ ). The wide-angle XRD patterns (Figure 1B) reveal that the anatase $\mathrm{TiO}_{2}$ begins to form in $\mathrm{Pd} / \mathrm{Ti}-\mathrm{SBA}-$ $15(10)$, as the appearance of the diffraction peaks at $2 \theta=37.8,48.4,54.7$, and $63.5^{\circ}$ [22]. This result suggests that a limited amount of titanium can be incorporated into SBA-15 framework. Moreover, the diffraction peaks of $\mathrm{Pd}$ are visible in neither of curves.

\section{$\mathbf{N}_{2}$ Adsorption/Desorption}

The results of $\mathrm{N}_{2}$ adsorption/desorption are shown in Figure 2 and Table 1. As it can be observed in Figure 2A, all catalysts exhibit type IV adsorption/desorption isotherms with H1-type hysteresis loop, which are typical characteristic of mesoporous materials according to the IUPAC classification [23]. Figure 2A shows that the sharpness of the steep rises as the $\mathrm{Si} / \mathrm{Ti}$ molar ratio increases from 10 to 80, indicating that the titanium atoms makes a broader mesopore size distribution as the sharpness of the adsorption branch suggests the uniformity of the mesopore size distribution [24]. This result can be verified by the 


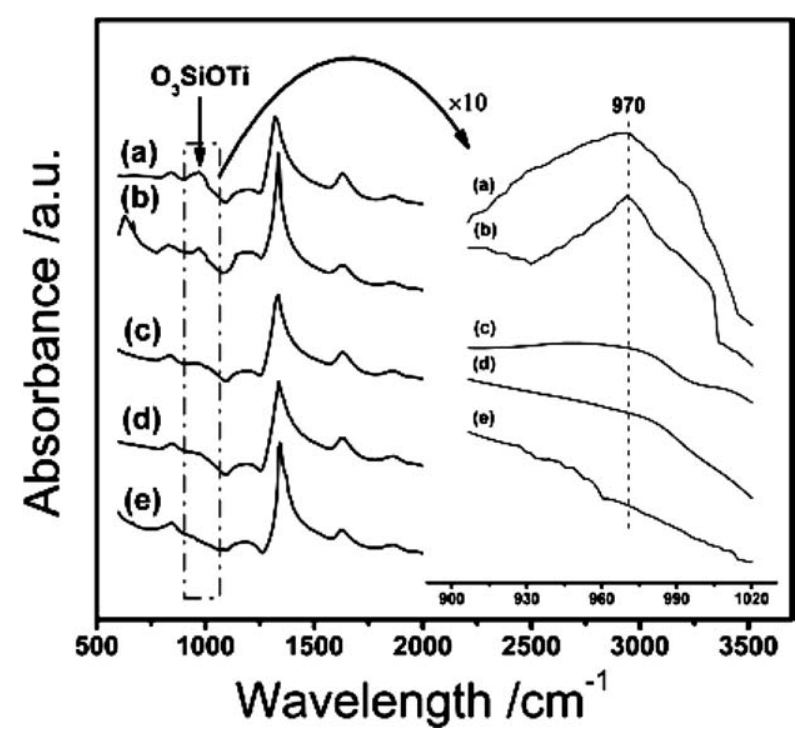

Figure 3. FT-IR spectra in the $600-2000 \mathrm{~cm}^{-1}$ range of (a) Pd/Ti-SBA-15(10), (b) Pd/Ti-SBA-15(20), (c) Pd/Ti-SBA-15(40), (d) Pd/Ti-SBA-15(80), and (e) Pd/ SBA-15.
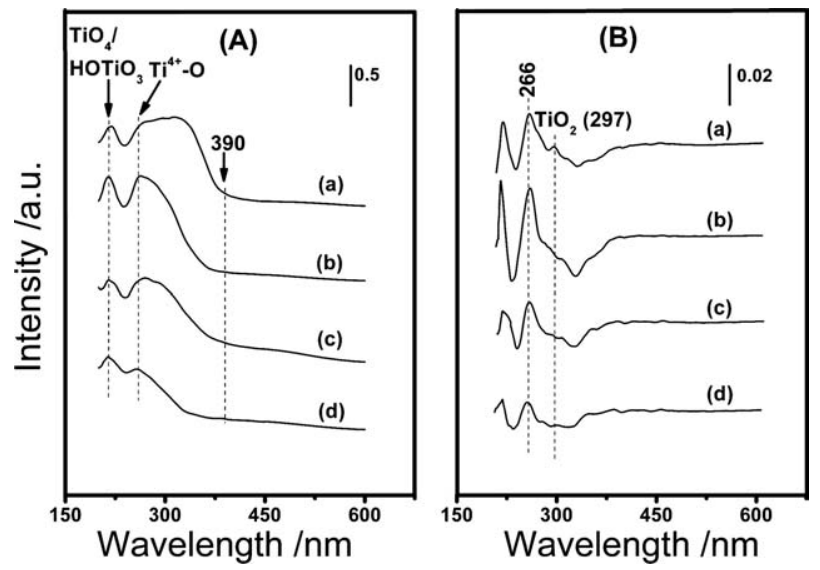

Figure 4. DRUV-vis spectra of Pd/Ti-SBA-15(x) catalysts (A) and its differentiated curve (B): (a) Pd/ Ti-SBA-15(10), (b) Pd/Ti-SBA-15(20), (c) Pd/Ti-SBA15(40), and (d) Pd/Ti-SBA-15(80).

pore size distribution curves (Figure 2B). The experimental result shows that the specific surface area and total pore volume of Pd/Ti-SBA-15(x) decreased with the rising of the $\mathrm{Ti} / \mathrm{Si}$ ratio. However, the $\mathrm{Pd} / \mathrm{Ti}-\mathrm{SBA}-$ 15(20) possesses the largest average pore diameter $(5.8 \mathrm{~nm})$, and the average pore diameter decreased to $5.1 \mathrm{~nm}$ when there is a further decrease in the $\mathrm{Si} / \mathrm{Ti}$ ratio, which may be because of the formation of $\mathrm{TiO}_{2}$ crystal in pore channels (Figure 1B).

\section{FT-IR, DRUV-vis, and $\mathrm{NH}_{\mathbf{3}}$-TPD}

Fourier transform infrared spectroscopy (FT-IR) and DRUV-Vis were carried out as former reports illuminated that the $\mathrm{Ti}^{4+}$ ions could strengthen the

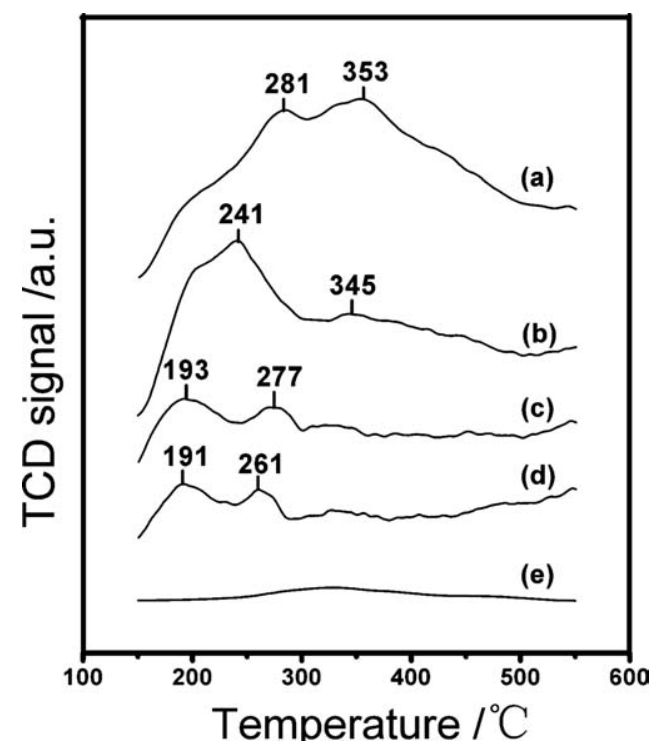

Figure 5. The $\mathrm{NH}_{3}$-TPD profiles of (a) Pd/Ti-SBA15(10), (b) Pd/Ti-SBA-15(20), (c) Pd/Ti-SBA-15(40), (d) Pd/Ti-SBA-15(80), and (e) Pd/SBA-15.

metal-support interaction, which can provide better dispersion for active phases [16-18]. Figure 3 shows that the peak at $1630 \mathrm{~cm}^{-1}$ is associated to the bending of $\mathrm{H}-\mathrm{O}-\mathrm{H}$ from adsorbed water, and the broad peak at $1185 \mathrm{~cm}^{-1}$ refers to the asymmetrical stretching of $\mathrm{Si}-\mathrm{O}-\mathrm{Si}$ within the mesoporous structure [25]. The peak at $820 \mathrm{~cm}^{-1}$ accounts for the asymmetrical stretching of $\mathrm{SiO}_{4}$ groups. The peak at 970 $\mathrm{cm}^{-1}$, with the intensity increasing with the $\mathrm{Ti} / \mathrm{Si}$ ratio increase, may be attributed to the stretching mode of $\mathrm{SiO}_{4}$ unit bonded to the $\mathrm{Ti}^{4+}$ ion [26]. This indicates that titanium is positioned in the SBA-15 framework (see Figure 3). The DRUV-vis patterns reveal that $\mathrm{Pd} /$ Ti-SBA-15(x) samples possess an adsorption peak at $216 \mathrm{~nm}$, and its intensity decreased with the rising of $\mathrm{Si} / \mathrm{Ti}$ ratio, which is directly connected with the framework $\mathrm{Ti}^{4+}$ with tetrahedral coordination [25]. An absorption peak with the maximum at $266 \mathrm{~nm}$ is also found for all curves, while the Pd/Ti-SBA-15(10) possesses a broader peak than the other samples. This adsorption peak is ascribed to the presence of a lowenergy charge-transfer transition between tetrahedral oxygen ligands and central $\mathrm{Ti}^{4+}$ ions [27]. Figure $4 \mathrm{~B}$ shows that the Pd/Ti-SBA-15(10) owns an absorption band with the maximum at $297 \mathrm{~nm}$, indicating the presence of $\mathrm{TiO}_{2}$ species [23]. Figure 5 shows that the $\mathrm{Pd} / \mathrm{SBA}-15$ sample possesses no desorption peak of $\mathrm{NH}_{3}$ and the framework titanium could introduce the weak acid sites to the support, where intensities increase in accordance with increase of amount of $\mathrm{NH}_{3}$ adsorbed, i.e., from $0.68 \mathrm{~mol} \mathrm{NH} / \mathrm{kgcat}$ for the sample having $\mathrm{Si} / \mathrm{Ti}=20$, and up to $1.87 \mathrm{~mol} \mathrm{NH}_{3} /$ kgcat for the sample with $\mathrm{Si} / \mathrm{Ti}=80$ molar ratio $(\mathrm{Ta}-$ ble 2) due to the presence of unsaturated $\mathrm{Ti}^{4+}$ sites [28]. Moreover, the strong acid sites begin forming (1.21 $\mathrm{mol} \mathrm{NH}_{3} / \mathrm{kg}$ cat.) when the $\mathrm{Si} / \mathrm{Ti}$ ratio $=10$. 
Table 2. Total acidity and density of acid sites of the catalysts.

\begin{tabular}{lccr}
\hline Catalysts & $\begin{array}{c}\boldsymbol{S}_{\mathbf{q}}^{*} \\
\mathbf{( m o l ~ N H}_{\mathbf{3}} \text { /kgcat) }\end{array}$ & $\begin{array}{c}\boldsymbol{W}_{\mathbf{q}}^{* * *} \\
\text { (mol NH}_{\mathbf{3}} \text { /kgcat) }\end{array}$ & $\begin{array}{c}\boldsymbol{T}^{\dagger} \\
\left.\mathbf{m o l ~ N H}_{\mathbf{3}} / \mathbf{k g c a t}\right)\end{array}$ \\
\hline Pd/Ti-SBA-15(10) & 1.21 & 0.31 & 1.52 \\
Pd/Ti-SBA-15(20) & 0.17 & 1.87 & 2.04 \\
Pd/Ti-SBA-15(40) & - & 0.98 & 0.98 \\
Pd/Ti-SBA-15(80) & - & 0.68 & 0.68 \\
\hline
\end{tabular}

*Amount of desorbed $\mathrm{NH}_{3}$ on strong acid sites.

**A Amount of desorbed $\mathrm{NH}_{3}$ on weak acid sites.

${ }^{\dagger}$ Total amount of desorbed $\mathrm{NH}_{3}$.

\section{SEM and TEM}

Figure 6A reveals that $\mathrm{Pd} / \mathrm{Ti}-\mathrm{SBA}-15(20)$ sample presents a large bunched, pipe-like structure with relatively uniform morphology, which is the typical morphology of ordered mesoporous SBA-15 [29]. Figure $6 \mathrm{~B}$ shows that the $\mathrm{Ti}-\mathrm{SBA}-15(\mathrm{Si} / \mathrm{Ti}$ molar ratio $=$ 20) possesses well developed parallel pore channels with uniform diameter of ca. $7 \mathrm{~nm}$, indicating that the incorporation of titanium does not influence the original structure of SBA-15. Figure 6C shows the TEM image of $\mathrm{Pd} / \mathrm{SBA}-15$, which is easy to find that the Pd/SBA-15 shows straight pore channel with uniform pore diameter of ca. 5-6 nm, and the palladium particles are well dispersed on it with an average diameter of ca. $6.7 \mathrm{~nm}$ (Figure 6E). Figure 6D shows the TEM profile of Pd/Ti-SBA-15(20) and the palladium atoms are better dispersed on it with a mean diameter of ca. $5.5 \mathrm{~nm}$ (Figure 6F). On the other hand, the catalyst structure is unstable (BET surface area decreases from 729.6 to $565.4 \mathrm{~m}^{2} / \mathrm{g}$ ) and the mean Pd particles over the support increase about $2 \mathrm{~nm}$ when the calcinations temperature increases from 600 to $800^{\circ} \mathrm{C}$, as can be seen in Table 1 and Figure $6 \mathrm{H}$.

\section{Catalytic Oxidation of Benzene}

The conversion values in the plot are calculated based on the concentration of benzene in the inlet and outlet gas. No benzene conversion was detected below $500^{\circ} \mathrm{C}$ in the absence of catalysts, and the products detected in the effluent are only $\mathrm{CO}_{2}$ and $\mathrm{H}_{2} \mathrm{O}$. Figure 7A obviously reveals that all the $\mathrm{Pd} / \mathrm{Ti}-\mathrm{SBA}-$ $15(\mathrm{x})$ samples possess higher activity than the $\mathrm{Pd} /$ $\mathrm{TiO}_{2}$ and $\mathrm{Pd} / \mathrm{SBA}-15$, indicating that titanium is beneficial for enhancing the catalytic activity. Among these catalysts, Pd/Ti-SBA-15(20) owns the best activity (followed by Pd/Ti-SBA-15(10)), which can complete the elimination of benzene at $240^{\circ} \mathrm{C}$, and this reaction temperature is lower than the other SBA-15 supported catalysts [3, 11, 12]. Some decrease could be observed when further raising the $\mathrm{Si} / \mathrm{Ti}$ molar ratio from 20 to 80. This result can be explained as follows: Firstly, the TEM results reveal that the proper level of titanium can provide better dispersion of active phase, and this conclusion was gained on other catalysts [16-18, 30]. Secondly, the Pd/Ti-SBA-15(20) has the largest average pore diameter (Table 1). As a consequence, ben- zene molecules are much easier to enter the pore channels and react on the active sites. On the other hand, the larger pore size is also beneficial for the diffusion and desorption of reaction products, such as $\mathrm{CO}_{2}$ and $\mathrm{H}_{2} \mathrm{O}$, during catalytic reactions. Thirdly, the incorporation of titanium could generate lots of acid sites (see Figure 5), which are good for the active sites dispersion. As for the active phase in VOCs oxidation over Pd-supported catalysts, i.e., $\mathrm{Pd}^{0}, \mathrm{Pd}^{2+}$, or a mixed $\mathrm{Pd}^{0} / \mathrm{Pd}^{2+}$ phase, most investigators propose that $\mathrm{Pd}^{2+}$ is active in hydrocarbons combustion, and the presence of $\mathrm{Pd}^{0}$ can enhance the catalytic activity by providing more active sites for VOCs dissociation and allowing the overall reaction to proceed more rapidly [31, 32]. As known, the two-step redox model (according to the following Eqs. 1 and 2) was proposed for oxidation of hydrocarbons (HCs) over supported Pd catalysts [33]:

$\mathrm{HC}+\mathrm{Cat}-\mathrm{O} \stackrel{k_{\mathrm{i}}}{\longrightarrow} \mathrm{Cat}+\mathrm{CO}_{2}$

That is, the oxidized catalyst is reduced by $\mathrm{HC}$, and $\mathrm{HC}$ is oxidized to $\mathrm{CO}_{2}$ on the catalyst surface and then $\mathrm{CO}_{2}$ is desorbed from the surface to the gas stream.

$\alpha \mathrm{O}_{2}+2 \mathrm{Cat} \stackrel{k_{\mathrm{oi}}}{\longrightarrow} 2 \mathrm{Cat}-\alpha \mathrm{O}$

where $k_{\mathrm{i}}$ is kinetic constant for the reaction between chemisorbed oxygen and VOCs, $k_{\mathrm{O} i}$ is the kinetic constant for the non-equilibrium dissociative adsorption of oxygen on catalyst surface, and $\alpha$ stands for the stoichiometric coefficient for the total combustion reaction $\left(\mathrm{mol} \mathrm{O}_{2} / \mathrm{mol} \mathrm{VOC}\right)$. In the second step, the catalyst redox center is oxidized by $\mathrm{O}_{2}$ to recover the active oxidized centers through adsorption and dissociation of $\mathrm{O}_{2}$ on the Pd surface. The larger pore size is proposed to promote desorption of $\mathrm{CO}_{2}$ from the catalyst surface, therefore step (1) could be directly facilitated, and simultaneously more reduced catalytic centers are released and reaction (2) is speeded up. The evaluation result of $\mathrm{Pd} / \mathrm{Ti}-\mathrm{SBA}-15(\mathrm{y})$ and $\mathrm{Pd} / \mathrm{Ti}-$ SBA-15(z) samples shows that the calcinations temperature has more obvious effect on catalytic activity 

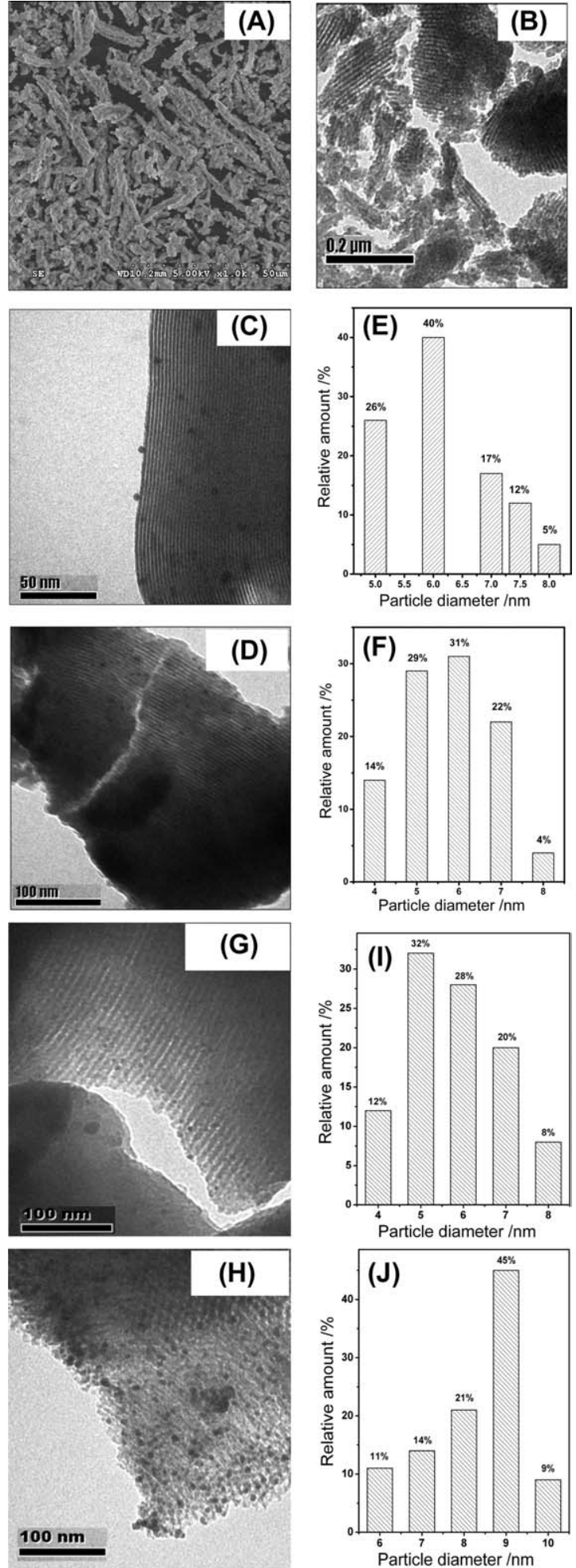

Figure 6. SEM, TEM patterns of catalysts, and Pd particle size distribution over the supports. SEM: (A) Pd/ Ti-SBA-15(20); TEM: (B) Ti-SBA-15(20), (C) Pd/SBA15, (D) Pd/Ti-SBA-15(20), (G) Pd/Ti-SBA-15(800), and $(\mathrm{H}) \mathrm{Pd} / \mathrm{Ti}-\mathrm{SBA}-15(600)$; (E) Pd particle size distribution over Pd/SBA-15, (F) Pd particle size distribution over Pd/Ti-SBA-15(20), (I) Pd particle size distribution over Pd/Ti-SBA-15(600), and (J) Pd particle size distribution over Pd/Ti-SBA-15(800).

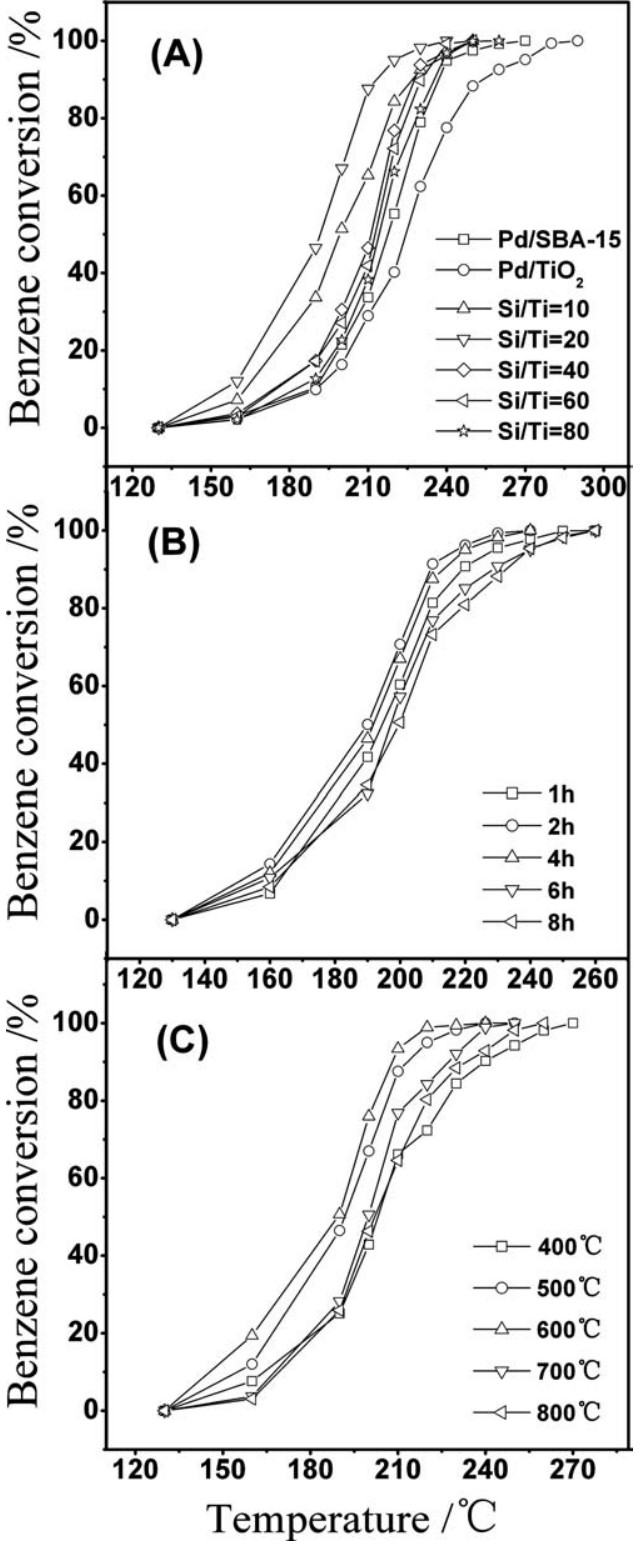

Figure 7. Conversion curves of benzene over various catalysts. (B: the Pd/Ti-SBA-15 catalysts with calcinations temperature and $\mathrm{Si} / \mathrm{Ti}$ molar ratio were fixed to $500^{\circ} \mathrm{C}$ and 20 , respectively; C: the $\mathrm{Pd} / \mathrm{Ti}-\mathrm{SBA}-15$ catalysts calcinations time and $\mathrm{Si} / \mathrm{Ti}$ molar ratio were fixed to $4 \mathrm{~h}$ and 20, respectively).

than calcinations time (Figures $7 \mathrm{~B}$ and $7 \mathrm{C}$ ), and the best calcinations time and temperature are $2-4 \mathrm{~h}$ and $600^{\circ} \mathrm{C}$, respectively.

\section{Stability Tests of Catalysts}

The stability of the catalysts is crucial in application because the reaction products (such as water) could possibly cause the change of the catalysts surface, decreasing the catalytic activity. Further tests for the durability of Pd/SBA-15 and Pd/Ti-SBA-15(20) catalysts were performed (Figure 8). The reaction temperature kept at 240 and $200^{\circ} \mathrm{C}$, respectively. The evaluation result reveals that the $\mathrm{Pd} / \mathrm{SBA}-15$ and 


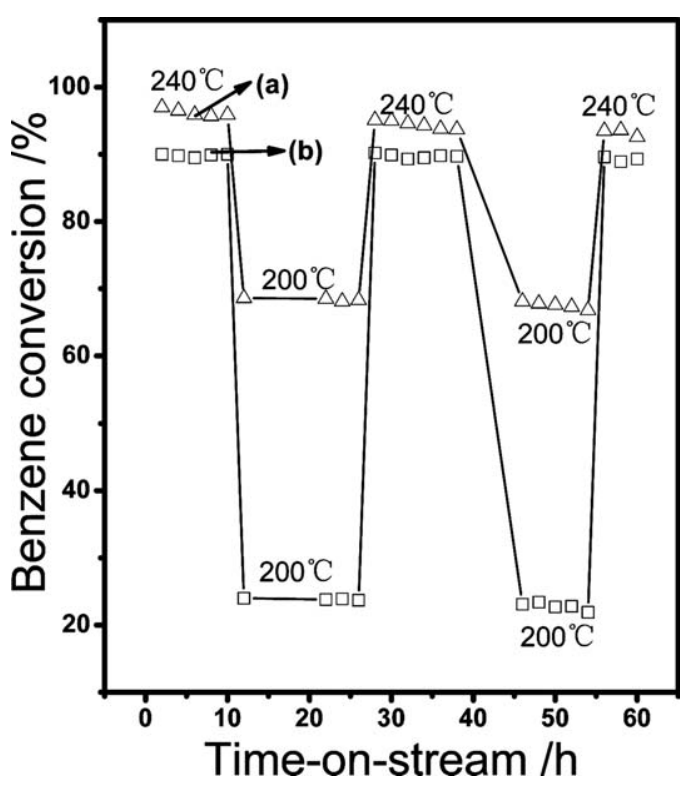

Figure 8. Stability tests with time-on-stream over different catalysts: (a) Pd/SBA-15; (b) Pd/Ti-SBA-15(20).

Pd/Ti-SBA-15(20) have no noticeable activity loss, indicating that the catalytic performance of both catalysts is well-sustained. As a consequence, the as-prepared Ti-modified mesoporous material is a promising catalyst for the potential application in catalytic oxidation of benzene-like VOCs.

\section{CONCLUSIONS}

$\mathrm{Pd} / \mathrm{Ti}-\mathrm{SBA}-15(\mathrm{x})$ catalysts with various Ti contents have been used for catalytic elimination of benzene, and the feasibility of Ti incorporation was explored in detail in this work. The characterization results reveal that all supports maintain their original structure after $\mathrm{Ti}$ incorporation and the framework $\mathrm{Ti}$ leads to a better dispersion of active redox Pd. Moreover, Pd/Ti-SBA-15(x) catalysts possess narrow pore size distribution, high specific surface area, and total pore volume. The framework titanium mainly located in the tetrahedral position and anatase $\mathrm{TiO}_{2}$ forms in the pore channels of Pd/Ti-SBA-15(10). In addition, titanium could generate the strong and weak $(\mathrm{Si} / \mathrm{Ti}=$ 10) acid sites in the catalysts. The evaluation results reveal that $\mathrm{Pd} / \mathrm{Ti}-\mathrm{SBA}-15(\mathrm{x})$ catalysts show higher activity than $\mathrm{Pd} / \mathrm{TiO}_{2}$ and $\mathrm{Pd} / \mathrm{SBA}-15$, and $\mathrm{Pd} / \mathrm{Ti}-\mathrm{SBA}-$ 15(20) possesses the best activity and an excellent durability. Moreover, the calcinations temperature has more obvious effect on the activity than the calcinations time, and the best calcinations time and temperature are $2-4 \mathrm{~h}$ and $600^{\circ} \mathrm{C}$, respectively.

\section{ACKNOWLEDGMENTS}

The support from the National Science Fund for Distinguished Young Scholars (No. 20725723), the National Basic Research Program of China (No. 2010CB732300), and National High Technology
Research and Development Program of China (No. 2006AA06A310) are gratefully acknowledged.

\section{LITERATURE CITED}

1. Li, J.J., Xu, X.Y., Jiang, Z., Hao, Z.P., \& Hu, C. (2005). Nanoporous silica-supported nanometric palladium: Synthesis, characterization, and catalytic deep oxidation of benzene, Environmental Science and Technology, 39, 1319-1323.

2. Li, J.J., Jiang, Z., Hao, Z.P., Xu, X.Y., \& Zhuang, Y.H. (2005). Pillared laponite clays-supported palladium catalysts for the complete oxidation of benzene, Journal of Molecular Catalysis A: Chemical, 225, 173-179.

3. Mu, Z., Li, J.J., Duan, M.H., Hao, Z.P., \& Qiao, S.Z. (2008). Catalytic combustion of benzene on $\mathrm{Co} / \mathrm{CeO}_{2} / \mathrm{SBA}-15$ and Co/SBA-15 catalysts, Catalysis Communications, 9, 1874-1877.

4. Lucas, A.D., Valverde, J.L., Sánchez, P., Dorado, F., \& Ramos, M.J. (2005). Hydroisomerization of n-octane over platinum catalysts with or without binder, Applied Catalysis A: General, 282, 15-24.

5. Kresge, C.T., Leonowicz, M.E., Roth, W.J., Vartuli, C.J., \& Beck, J.S. (1992). Ordered mesoporous molecular sieves synthesized by a liquid-crystal template mechanism, Nature, 359, 710-712.

6. Deutsch, J., Prescott, H.A., Muller, D., \& Kemnitz, E. (2005). The effect of phosphate and glycol on the sulfidation mechanism of $\mathrm{CoMo} / \mathrm{Al}_{2} \mathrm{O}_{3}$ hydrotreating catalysts: An in situ QEXAFS study, Journal of Catalysis, 231, 259-268.

7. Morey, M.S., O'Brien, S., Schwarz, S., \& Stucky, G.D. (2000). Hydrothermal and postsynthesis surface modification of cubic MCM-48, and ultralarge pore SBA-15 mesoporous silica with titanium, Chemistry of Materials, 12, 898-911.

8. Bharat, L.N., Johnson, O., \& Sridhar, K. (2001). Direct synthesis of titanium-substituted mesoporous SBA-15 molecular sieve under microwavehydrothermal conditions, Chemistry of Materials, 13, 552-557.

9. Chen, Y.Y., Huang, Y.L., Xiu, J.H., Han, X.W., \& Bao, X.H. (2004). Direct synthesis, characterization and catalytic activity of titanium-substituted SBA-15 mesoporous molecular sieves, Applied Catalysis A: General, 273, 185-191.

10. Zhang, W.H., Lu, J., Han, B., Li, M., Xiu, J., Ying, P., \& Li, C. (2002). Direct synthesis and characterization of titanium-substituted mesoporous molecular sieve SBA-15, Chemistry of Materials, 14, 3413-3421.

11. Yang, J.S., Jung, W.Y., Lee, G.D., Park, S.S., Jeong, E.D., Kim, H.G., \& Hong, S.S. (2008). Catalytic combustion of benzene over metal oxides supported on SBA-15, Journal of Industrial and Engineering Chemistry, 14, 779-784.

12. Li, J.J., Xu, X.Y., Hao, Z.P., \& Zhao, W. (2008). Mesoporous silica supported cobalt oxide catalysts for catalytic removal of benzene, Journal of Porous Materials, 15, 163-169.

13. Garcia, T., Solsona, B., Cazorla-Amorós, D., Linares-Solano, Á., \& Taylor, S.H. (2006). Total oxidation of volatile organic compounds by vana- 
dium promoted palladium-titania catalysts: Comparison of aromatic and polyaromatic compounds, Applied Catalysis B: Environmental, 62, 66-76.

14. Hong, S.S., Lee, G.H., \& Lee, G.D. (2003). Catalytic combustion of benzene over supported metal oxides catalysts, Korean Journal of Chemical Engineering, 20, 440-444.

15. Debecker, D.P., Delaigle, R., Eloy, P., \& Gaigneaux, E.M. (2008). Abatement of model molecules for dioxin total oxidation on $\mathrm{V}_{2} \mathrm{O}_{5^{-}}$ $\mathrm{WO}_{3} / \mathrm{TiO}_{2}$ catalysts: The case of substituted oxygen-containing VOC, Journal of Molecular Catalysis A: Chemical, 289, 38-43.

16. Zepeda, T.A., Pawelec, B., Fierro, J.L.G., \& Halachev, T. (2007). Removal of refractory S-containing compounds from liquid fuels on novel bifunctional CoMo/HMS catalysts modified with Ti, Applied Catalysis B: Environmental, 71, 223-236.

17. Shimada, H. (2003). Morphology and orientation of $\mathrm{MoS}_{2}$ clusters on $\mathrm{Al}_{2} \mathrm{O}_{3}$ and $\mathrm{TiO}_{2}$ supports and their effect on catalytic performance, Catalysis Today, 86, 17-29.

18. Yoshinaka, S., \& Segawa, K. (1998). Hydrodesulfurization of dibenzothiophenes over molybdenum catalyst supported on $\mathrm{TiO}_{2}-\mathrm{Al}_{2} \mathrm{O}_{3}$, Catalysis Today, 45, 293-298.

19. Wang, G.H. (2007). Hydrothermal synthesis and photocatalytic activity of nanocrystalline $\mathrm{TiO}_{2}$ powders in ethanol-water mixed solutions, Journal of Molecular Catalysis A: Chemical, 274, 185-191.

20. Srivastava, R., Srinivas, D., \& Ratnasamy, P. (2005). $\mathrm{CO}_{2}$ activation and synthesis of cyclic carbonates and alkyl/aryl carbamates over adeninemodified Ti-SBA-15 solid catalysts, Journal of Catalysis, 233, 1-15.

21. Jung, W.Y., Baek, S.H., Yang, J.S., Lim, K.T., Lee, M.S., Lee, G.D., Park, S.S., \& Hong, S.S. (2008). Synthesis of Ti-containing SBA-15 materials and studies on their photocatalytic decomposition of orange II, Catalysis Today, 131, 437-443.

22. Li, G. \& Zhao, X.S. (2006). Characterization and photocatalytic properties of titanium-containing mesoporous SBA-15, Industrial and Engineering Chemistry Research, 45, 3569-3573.

23. Sing, K.S.W., Everett, D.H., Haul, R.A.W., Moscow, L., Pierotti, R.A., Rouquero, L.J., \& Siemieniewska, T. (1985). Reporting physisorption data for gas/solid systems with special reference to the determination of surface area and porosity, Pure and Applied Chemistry, 57, 603-619.
24. Newalkar, B.L., Olanrewaju, J., \& Komarneni, S. (2001). Direct synthesis of titanium-substituted mesoporous SBA-15 molecular sieve under microwave-hydrothermal conditions, Chemistry of Materials, 13, 552-557.

25. Araújo, R.S., Azevedo, D.C.S., Rodríguez-Castellón, E., Jiménez-López, A., \& Cavalcante, C.L., Jr. (2008). Al and Ti-containing mesoporous molecular sieves: Synthesis, characterization and redox activity in the anthracene oxidation, Journal of Molecular Catalysis A: Chemical, 281, 154-163.

26. Boccuti, M.R., Rao, K.M., Zecchina, A., Leofanti, G., \& Petrini, G. (1989). Spectroscopic characterization of silicalite and titanium-silicalite, Studies in Surface Science and Catalysis, 48, 133-144.

27. Luan, Z. \& Kevan, L. (1997). Electron spin resonance and diffuse reflectance ultraviolet-visible spectroscopies of vanadium immobilized at surface titanium centers of titanosilicate mesoporous Ti-MCM-41 molecular sieves, The Journal of Physical Chemistry B, 101, 2020-2027.

28. Gutiérrez, O.Y., Fuentes, G.A., Salcedo, C., \& Klimova, T. (2006). SBA-15 supports modified by $\mathrm{Ti}$ and $\mathrm{Zr}$ grafting for NiMo hydrodesulfurization catalysts, Catalysis Today, 116, 485.

29. Hartmann, M. \& Vinu, A. (2002). Mechanical stability and porosity analysis of large-pore SBA-15 mesoporous molecular sieves by mercury porosimetry and organics adsorption, Langmuir, 18, 8010-8016.

30. Anderson, J., Fergusson, C., Rodriguez-Ramos, I., \& Guerrero-Ruiz, A. (2000). Influence of $\mathrm{Si} / \mathrm{Zr}$ ratio on the formation of surface acidity in silicazirconia aerogels, Journal of Catalysis, 192, 344354.

31. Yin, F.J., Ji, S.F., Wu, P.Y., Zhao, F.Z., \& Li, C.Y. (2008). Deactivation behavior of Pd-based SBA15 mesoporous silica catalysts for the catalytic combustion of methane, Journal of Catalysis, 257, 108-116.

32. Shim, W.G., Lee, J.W., \& Kim, S.C. (2008). Analysis of catalytic oxidation of aromatic hydrocarbons over supported palladium catalyst with different pretreatments based on heterogeneous adsorption properties, Applied Catalysis B: Environmental, 84, 133-141.

33. Dangi, S., \& Abraham, M.A. (1997). Kinetics and modeling of mixture effects during complete catalytic oxidation of benzene and methyl tert-butyl ether, Industrial and Engineering Chemistry Research, 36, 1979-1988. 